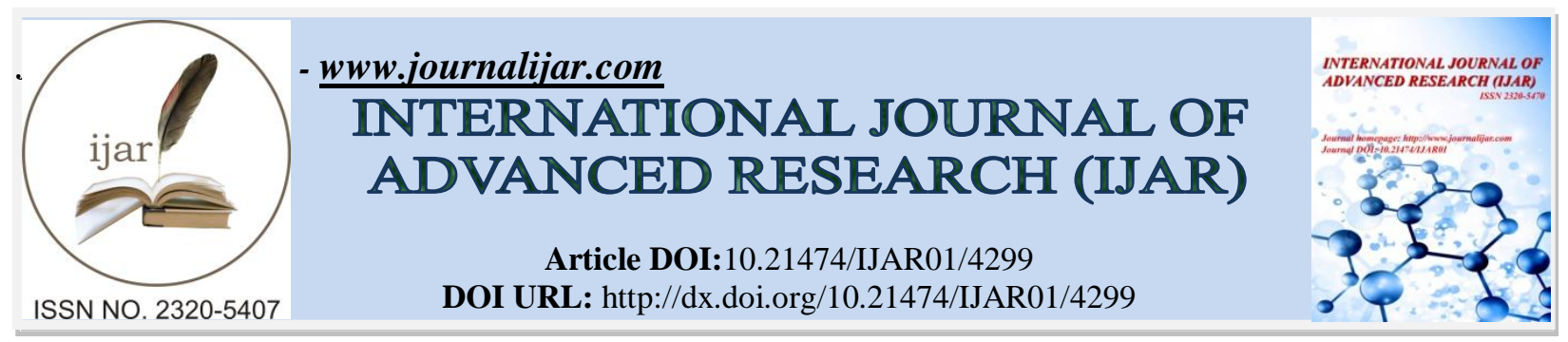

RESEARCH ARTICLE

\title{
THE INFLUENCE OF INCENTIVES ON PERFORMANCE AND AGENCY ISSUES (CASE STUDY IN PRINCIPALS - AGENTS RELATION IN RSU-BLUD BAHTERAMAS, KENDARI CITY SOUTHEAST SULAWESI PROVINCE.
}

ZainulAbidin.

Lecturer of State Administration Program University DayanuIkhsanuddin.

\section{Manuscript Info} .....................

\section{Manuscript History}

Received: 18 March 2017

Final Accepted: 22 April 2017

Published: May 2017

\section{Abstract}

Provincial Government of Southeast Sulawesi as the principal has entrusted to the agency that the public hospital bahteramas, especially the ranks of managers to make optimum efforts to pursue the target set. Agent's function can cause agency problems. Which arises from the desire of the principal and the opposing agent and the problem of risk sharing consequently. One of the elements causing the agency problem is the incentive in the principal relation with the agent. This research aims to analyze the influence of incentives on the performance and effort of pressing the agency problem in bahteramas hospital Kendari City, Province Southeast Sulawesi. This research uses a qualitative approach. The results show that incentives can not always help improve performance and overcome the agency problems. The incentives that exist are less to encourage organizations and individuals to optimize their business. Adverse selection and moral hazard also still occur either potential or factual.

Copy Right, IJAR, 2017,. All rights reserved.

\section{Chapter I:- \\ Preliminary:-}

One theory that can be used in public service is agency theory. This theory is widely described in the economic, political and organizational behavior. Principals are parties who need services of goods and services while agents are parties who provide services. So it can be viewed as a contractual model between two or more people, one of the parties is called the agent and the other is called the principal. In the theory of the agency described separation between ownership of the company begins with the giving of control of the residual to the agent, namely the right to make decisions under certain conditions. The control of the residuals owned by the agent makes it possible to divert and the difficulty of the principal gain confidence that the principal wealth is properly managed. The possible possibility is that the agent can execute the principle of the principal and direct the occurrence of opportunistic attitudes. The expropriation of agents can be done in various forms, ranging from embezzlement and the most severe in the form of retaining office even though it is incompetent in running its business (Scott, 1995). Eisenhardt (1989) explains there are four aspects that can be analyzed in the principal-agent relationship of incentives, risks, result uncertainties and information systems. One way to bridge the principal's interests and prevent or minimize abuse is the incentive mechanism. Incentives are expected to improve organizational performance and curb agent opportunism. Thus, incentives are also tasked with preventing or minimizing agency issues both adverse selection and moral hazard. 
In the context of this study the principal is the provincial government of Southeast Sulawesi and the agent is Bahteramasmasrsu-blud, especially its managerial ranks. This research intends to focus on analyzing the principal relations and agents there from the incentive aspect.

\section{Chapter II}

\section{Literature Review:-}

\section{A. Agency Theory:-}

Roots of Ideas and Assumptions:-

Bhalchandra (1998) states that agency theory was born from Berle and Means thinking in 1932 which examines the transfer of authority from owner to manager. Both researchers suggest that managers are people who can not be trusted fully and have separate goals with principal objectives.

The core idea of agency relationships is the separation between ownership and control that focuses on controls on agents, which then implicates the discussion of conflicting interests between agents and principals. Broadly speaking, agency theory is intended to solve two problems in agency relationships. First, agency problems arise when the desires of the principal and the agent are opposite and it is expensive for the principal to verify what the agent actually does. Secondly, there is a problem of risk sharing when principals and agents have different attitudes toward risk.

The agency theory bases on several assumptions. First, assumptions about human nature. This assumption emphasizes that human beings always put their own interests first, always try to avoid risk and human beings are considered to have limited rationality. Secondly, organizational assumptions, organization is considered always conflict of intentions between parties The information is asymmetric between principal and agent, and efficiency as a criterion of effectiveness. Thirdly, the assumption of information is that information as a commodity that can be traded (Eisenhardt, 1989).

The phenomenon of agency relationships is becoming increasingly appealing, due to the emergence of moral hazard and adverse selection.Moraldhazzard refers to the lack of effort of the agents. The argument here is that agents can easily actually implement what has been agreed upon. By him agents are said to be lazy or avoid work. Adverse selection refers to the inadequacy of presenting capabilities by agents.

\section{Agency Problem:-}

Agents, as assumed, tend to put their interests first priority over the principal's interests. As an effort to overcome the tendency to deviate agents and based on the agency theory analysis unit, the key lies in the determination of the contract underlying the relationship between the principal and the agent itself. Killick (1997) describes an agent's relationship as a contract in which one party called the principal involves another party that is the agent to perform the service. The principal has the hope that the agent can fulfill the interests of the principal. On the other hand, the agent also needs a fee to pursue his own goals. Agency problems thus arise due to imperfections of contracts to agent actions that affect the well-being of agents and the welfare of the principals. Due to agency problem is the existence of agency cost.

\section{Incentives Aspect In Principal - Agent Relation:-}

According to Eisenhardt (1989) agency theory is similar to the model of political approach within the organization. The two perspectives of agency theory and political models assume the pursuit of self-interest at the individual level and the existence of conflicts of interest at the organizational level. The difference is that in the political model differences of interest are saturated through negotiations, coalitions and power mechanisms of political science. Whereas in agency theory are given solutions through incentive and cost mechanisms in the economy.

The effect of financial incentives on performance on agency theory is explained by one of its assumptions that individuals are rational and maximize their utility expectations. Individuals tend to neglect their jobs unless they can contribute to their economic well-being. Incentives have a fundamental role in motivating and controlling performance because incentives are a means to maximize the well-being of individuals. Thus, linking incentives with agency performance is one way to reduce agency conflicts arising from differences in individualist interests and behavior. That incentives linked to performance can help overcome moral hazard problems. The agency theory determines the use of incentives when the principal can not observe agent actions. The principal feels confident that managers will make optimal decisions when there is adequate incentive and gain supervision 
from the principal. Principals want a return on the investment they invest in while the agency wants to provide compensation or incentives for its performance in running the company. The main role of principals is to administer incentive schemes to manage agendas in a better credible way than to monitor agents. The hope is that if the principal gives the right incentives appropriately, the organization becomes a self-administered entity in the very moment that it does not have to do strict supervision to convince the behavior of the entrepreneur with the expectation of the principal.

\section{Chapter III:- \\ Research Methods:-}

This research uses qualitative approach. Qualitative research is a study that focuses on interpretation and understanding (Creswell, 2003). According to Irawan (2006), qualitative research has a unique study because it questioned the meaning of an object where the researcher himself must be the main instrument. The research strategy used case study. This strategy makes it possible to focus on an organization, a policy, even a state as a social unit (Moleong, 1994).

The data analysis used in this research is an interactive analytical model from Miles and Huberman (1994). This model includes data reduction, data presentation, inference and verification. The data is presented in the form of narrative text to describe what happened. The author makes the initial conclusions and verifies the data presented by confirming through triangulation.

\section{Chapter IV:-}

Results and Discussion:-

The Existence of Incentives at Bahteramas Public Hospital:-

Provision of incentives for hospital staff stipulated by the director of the hospital refers to the governor regulation of Southeast Sulawesi on guidelines for determining remuneration for management officials, supervisory boards, other professionals and hospital bahteramasblud employees. It is stated that Article 10 of the regulation is the amount of incentives or services, bonuses or achievements and severance pay for cumulative RSU employees is set at a maximum of $44 \%$ of the total functional income of the house. Subsequently it was agreed that the division of incentives was 5\% for the board of directors and $95 \%$ for the functional and administrative personnel with details of the distribution of $40 \%$ for medical personnel, $47 \%$ for paramedical personnel including nurses, midwives, nutrious, maintenance and similar facilities and 13\% for administrative personnel. Government Regulation number 23 of 2005 on finance of public service agency (BLU) mentions BLU aims to improve services to the public. With the demands of performance improvement it is only natural that BLUD employees get incentives that are tailored to the BLUD's own capabilities. The incentives for functional position holders (functional health and nursing) are based on grouping of positions and employee groups. Assistant 3 The provincial government of Southeast Sulawesi states:

Provision of basic benefits of the province is actually an effort made by the government to provide stimulus for employees to be able to carry out their duties properly. While the remuneration is a way that can be given to appreciate medical personnel, especially doctors and provide stimulation for the doctors. As I recall the reference to the Ministry of Home Affairs's regulation of local financial management guidelines, local governments can provide additional income to civil servants. The amount of remuneration, can be adjusted to the financial condition of the hospital and local government. My reminder for the TPP was based echelon. Echelon four about one million six hundred thousand, echelon three two million three hundred and echelon two three million rupiah (Interview, August 18, 2016).

\section{Effect of Incentives on Performance:-}

The agency theory determines the use of performance incentives when the principal can not observe the agent's actions. The principal feels that managers will make optimal decisions when there are adequate incentives. The main role of the principal is to administer an incentive scheme to manage agendas in a better credible manner than to monitor agents. The purpose of incentives is to improve structures in the bureaucracy and the performance of government employees. So in agency theory explains that giving incentives should be proportional to performance.

One of the performance indicators used in the calculation of service incentives is attendance. Absence is used as an important indicator to see the level of employee discipline but should not be the only indicator to assess 
performance. If service incentives are not distinguished between high performing and low-performing nurses, highperforming nurses will lose their motivational power and degrade their performance.

The results of the interviews indicate that so far the provision of service incentives in Bahteramas hospitals cannot encourage the performance, especially the nurses. Incentives for doctors and nurses have a negative impact on employee motivation. In hopes, by increasing financial capacity, BLU leaders can improve service quality and improve Remuneration in return for employee performance. Although there are incentives in the form of TPP and medical services (remune) facts in the field have not shown a straight comparison with performance. The facts show good financial performance, but service and quality of service declined two years, meaning less evidence of incentives to make agents align and pursue principal interests to improve services for the community.

Performance appraisal system is one of the tools that can be used to assess a process of BLU activity of hospital continuously. The type of indicator that is assessed for hospital BLU according to health minister's decree no. 550 / Menkes / SK / VII / 2009 covers three aspects, namely: finance with weight 20, operational performance with weight 40 , quality of service and benefit for society with weight 40 . While financial performance measured from return on investment (ROI), current ratio (Liquidity), return on assets (ROA) and total asset turnover (TATO). RS BahteramasSultra own revenue fluctuated, but generally increased from 2010 to 2015 . The total revenue of Bahteramas Hospital in 2010 reached Rp. 23,943,133,251, deposited to regional treasury as PAD of Rp. 23.943.133.251 where the target deposit is only Rp. 14. 602 . 578.900 which means the achievement of the target deposit reached 163.97\%. The amount of revenue of Bahteramas Hospital 2014 reached Rp. 67,185,671,681, paid to the BLUD cash of Rp. 36.653.662.256 where the deposit target is Rp. 52.435. 544,622 which means the achievement of the target deposit reached $168.96 \%$. While in 2015 the amount of revenue reached Rp. 41,571,023,422, deposited into the BLUD cash of Rp. 38.455.342.231 where the target of the deposit is Rp. 35.232. 265,271 which means the achievement of target deposit reached $117.34 \%$. Other financial performance can be seen from liquidity, solvency and profitability. In terms of solvency can be seen between 2014 and 2015 there is a decrease for both ratios. In terms of debt to asset ratio decreased $49 \%$, which means bahteramas hospital to pay its long-term debt decreased by $-49 \%$ by paying attention to the ratio of total debt to assets. In terms of debt to equity decreased by $-48 \%$ which means to pay long-term debt decreased by-1.02\%. This is very good because the smaller the ratio the better. In terms of profitability of ROA in 2013 , amounted to $70.1 \%$ which means that every total assets of 1 rupiah produces a surplus of Rp. 0,701., And 2015 equal to 0,124 which mean each total asset equal to $\mathrm{Rp} 1$ produce surplus 0,124 rupiah. From ROE obtained 0,124 which mean every capital equal to Rp 1 yield surplus Rp.0,124.

In addition to financially, the performance can be used as another benchmark performance. Performance in question is the operational performance and quality of service performance and benefits for the community. Operational Performance among others is the bed occupancy rate (BOR), average length of stay (AVLOS), bed turn over (BTO). BOR is the percentage of bed usage in one particular unit. The ideal value of BOR is $60-85 \%$. According to the hospital profile document in 2015 the Bahoras BOR Bahteramas figure fluctuated from 57.60\% in 2013 to 58.45\% in 2014 and $57.12 \%$ in 2015. Overall, the BOR value is still considered inefficient because it did not reach Ideal rate $60 \%$. The second indicator is the average length of treatment (LOS). The ideal LOS is 6-9 days. The average LOS number in 2014 decreased from 2013 from 5.2 days to 4.8 days. However, it increased again to 5 days in 2015.Angkaini is still under ideal category according to kepmenkes that is 6-9 days. Third is the time interval between the use of the bed (TOI). TOI ideal value is 1-3 days or ideally empty beds only 1-3 days. Bahteramas RSU TOI figures in 2014 decreased compared to 3.8 in 2013 to 3.4 days, but again rose to 3.82 days in 2015 . The last is the number of bed frequency (BTO). The number of BTO frequencies in 2014 slightly increased from 40.5 times to 44.4 times and dropped to 42.7 times in 2015 . This value is still an ideal value.

The last non-financial performance is related to the quality of services and benefits to the community, including among others the general mortality rate (GDR), mortality rate> 48 hours (NDR) and referral inpatients referred. NDR is the patient's death rate within 48 hours after the patient is treated per hundred patients out. The tolerable NDR is less than 2.5 per 100 patients out. The overall NDR figure until 2015 has decreased. In hospitals Bahteramas showed NDR 2010 of 1.57, 2011 of 2.27, 2012 of 2.14, 2013 of 2.18, 2014 of 2.54 and 2.03 in 2015. NDR's ideal rate is nothing more than $2.5 \%$. The second indicator is the general mortality rate (GDR). The standard GDR score is no more than 4.5 per hundred patients out. The GDR in Bahteramas General Hospital from 2010 to 2015 has experienced a fluctuation of the normal limit of 4.5\%. The year 2010 is 4.25\%, 2011 is 4.17, $20124.48,20134.37$ and $20145.12 \%$ and $4.54 \%$ in 2015 . The ideal rate of GDR is not more than $4.5 \%$. 
From these three levels of performance, it can be seen that the performance to achieve the target is financial performance where the target of income, liquidity ability, solvency and rentability of hospital is relatively increased from 2010 until 2015. While operational performance and service quality for the community tend to decrease and not reach ideal target. From the operational side BOR, LOS, TOI and BTO figures show this, as well as the NDR and GDR in terms of service quality and benefits for the community. Whereas according to Kepmenkes number 550 in 2009 which became the benchmark of performance measurement, the weight of the financial performance is only $20 \%$, compared to the other two performance that weights $40 \%$ each. This is in accordance with the purpose of the BLU is not to prioritize the pursuit of profits but improving service performance and budget efficiency.

\section{Incentive Ability to Curb Agent Opportunity (Adverse Selection and Moral Hazard):- Adverse Selection at Bahteramas General Hospital:-}

The principal should know the nature of the task of the agent who must carry out the tasks and personal characteristics necessary to perform the task successfully. However, in adverse selection situations, the problem arises from the uncertainty of the principal's knowledge of the agent. If the moral hazard addresses the lack of agency effort, Adverse selection refers to the misrepresentation of agency capabilities.

\section{Agent Capacity and Will:-}

Eisendhardt (1989) and Kivisto (2007) looked at adverse selection of willingness and capacity. The aspect of the will can be determined as the real level of motivation in the RSUD in order to complete the task. A high level of goal conflict between principal and agent seems to reduce the level of motivation and willingness to complete the task. Then, the capacity aspect on the other hand can be related to determining the potential of the productivity quality of the RSUD. Together, the willingness and capacity aspect basically determines how effective and efficient hospitals will produce or produce tasks that have been agreed or determined.

Therefore, before the implementation of services, it is very important that the provincial government as principal to make decisions on how to allocate duties and funds to hospitals. This is related to the placement process performed by the head of the region and the head of the hospital to his subordinates. It could be that the placement of staff in RSUD is not as expected. This is because the information asymmetry that exists and assumed the importance of RSUD, then there will be an opportunity as an agent to make a deviation. In many practices, adverse selection issues can occur for example in the job market. Job applicants are usually different in type and employers do not always know the correct type of job applicant. Employers, for example, may not be able to observe the intrinsic productivity of job applicants and can not control the prospective employee's statement about their own attributes because all workers tend to claim that they are very capable. Therefore, employers may hire the wrong employees. Deputy director of 3 Bahteramas hospitals stated:

In some cases it is difficult to divide the task well. This happens in incidental and less programmed activities. With time and limited resources we have to divide the task. Under these circumstances there may be hidden and unknown information entered. Actual capabilities can also be less known. For example there is a sudden request from a company or NGO to perform free health services (Interview, August 18, 2016).

Without action to try to reduce information asymmetry, adverse selection issues can lead to a decrease in the average quality of the agents or products they offer. High quality agents may want to withdraw from the market if their quality is impossible to recognize at no additional cost. This problem was first highlighted by Akerlof (1970), which suggests that the process will continue until the lowest quality agents are available in the market. Adverse selections themselves can be reduced by expanding effort and attention. This can be done through a mechanism called screening and signaling. In examination, the principal makes the first step and selects the implementation of several sets of information gathering procedures to accurately determine the type of potential and appropriate agent. For example an employer may use a job interview and a trial period to learn about the applicant. In addition, he or she may require a recommendation letter or may trace previous employers in order to find out whether they have been satisfied with the applicant's work contribution (Bergen, 1992). Given that an agent knows he has certain desired abilities, and that it is for his benefit to be offered a contract, the agent can take actions aimed at signaling to the principal that he is the agent he is looking for (Bergen, 1992). Assistant of the provincial government of Southeast Sulawesi, LA said :

The provincial government has delegated duties to hospitals, of course with the belief that the hospital will provide maximum effort and provide the correct report from planning, implementation and evaluation. I believe hospitals in 
selecting implementers of programs and activities have chosen the best and experienced and this is often a consideration in government (Interview, August 18, 2016).

\section{S, as the special inspector of Southeast Sulawesi stated:-}

During this examination results show no serious problems. Hospitals would also want the best and keep improving. The problem that got our attention as I remember around 2012 where the hospital that occupies this new building is problematic in parking management. Parking there is run by a lot of thugs and his income does not enter the area. At that time the hospital did not report this. Later there is a fuss between thugs and our visit there we recommend new improvements. The problem that I recall was also about a drug store occupying one room. After getting feedback they do not give income either taxes or taxes we reprimand and recommend the hospital to pay rent and retribution. I do not know this is deliberately hidden or not, we just run the task (Interview, August 19, 2016).

Before the implementation of the contract between the provincial government as a principal and rsudbahteramas as an agent, provincial governments should be required to obtain information from rsudBahteramas. Given the information asymmetry, the provincial government needs to make proper checks to the Rsud, so the decision to choose the agency (implementing a program and activities) can help to minimize the problem. The contracts between the provincial government and rsudmesti were increased. Thus the authorization of rsud in carrying out the task of health services to the public needs to be done in detail so that the expected results are achieved. The provincial government clearly has information pertaining to the formal requirements of a civil servant. Although, their behavior as potential agents can not be predicted with detail by the provincial government.

To oversee agent behavior, at any time it is very difficult for the provincial government to do so. From the observation of rsud researchers, they work less discipline, especially the staff and administration. Where there are officers who often leave the place of duty, telling stories, listening to music, out of hospital during office hours. This behavior researchers get there during the research. Employees do exist and the majority are present in the room but with this behavior clearly indicates a lack of willingness. With the condition of the provincial government difficult to obtain information regarding the behavior of the officers at any time then the behavior of the lack of willingness to serve is difficult to identify other than by improving the monitoring or monitoring carried out with the mechanism as effectively as possible, either through a request report or make a direct visit to field or maximize the function of the hospital supervisory board.

From the description above, it can be said that the implementation of health services in rsudbahteramas also concerns adverse selection. Prior to service delivery, the provincial government made a decision on how to allocate tasks in the form of programs and activities. It is difficult for the provincial government to know with certainty the information asymmetry that can arise, especially in less programmed and incidental activities. Adverse selection involves two aspects of willingness and capacity. It could be in the allocation of activities and programs there is information hidden from the capacity and willingness of the implementer. The person who gets the task lacks the capacity and willingness to perform the task, and vice versa.

\section{Moral Hazard at Bahteramas General Hospital:-}

Moral hazard is a post-contract opportunism that utilizes information asymmetry on current performance (Barney \&Ouchi, 1986). The danger of this type of opportunism can be in the form of negligence or form of behavior favored by the agent, but not in the best interests of the principal. Eisenhardt (1989) and Kivisto (2007) explain basically every effort of the agent can turn into moral hazard behavior. Based on this assumption, there are four categories of moral hazard opportunism that illustrate some of their possible manifestations. Some of the frequent conditions of this opportunistic behavior arise with concrete examples of possible outcomes.

\section{Lazy or Shirking:-}

Lazy is a form of opportunistic behavior in which agents behave inappropriately or inappropriately than expected or where they do not work according to the orders given (Kivisto, 2007). The intensity of this laziness can be passive or aggressive. Concrete examples of this behavior of laziness are numerous. For example, a form of laziness can be a situation where hospital employees increase their free time widely to fulfill their institutional obligations. Taking minimal effort in doing service and making more efforts in terms of fulfilling personal interests including for example in increasing revenue or having fun like playing the internet in the room and not serving patients. Leisure shirking behavior is in direct observation of researchers is mostly done during the research there, especially the staff 
and administration. Many are fun to tell, calling for a long time and seem indifferent to patients who need service. Patients rsudBahteramas, TH said :

In my experience nurses usually postpone service and work while telling stories. But the administrative part of the service is worse than delaying, demanding and convoluted and less friendly (Interview, August 21, 2016).

The most important factor for reducing moral hazard in the form of laziness in agency theory is with incentives. Since the fondness for laziness is tied to intrinsic motivation, one of the most important issues is to deal with an incentive structure that either directly or indirectly prevents or promotes the emergence of laziness activity. Although the incentive system is also not always able to overcome the problem of laziness or negligence.Kivisto (2007) says a further incentive for laziness relating to the original (inside) incentive structure is linked to the level and form of salary at the organizational level.

\section{Opportunistic In Pursuing Prestige and Income:-}

In addition to the rare and uncoordinated laziness of individuals, opportunistic behavior can also take place in a collective and organized way at the institutional level. There are three main goals: prestige, excellence and influence. Since the pursuit of exten- sion, prestige and influence is usually very expensive, the primary staff of RSUD doctors are seeking as much as possible of extra income. IrbansusInspektorat, S said :

It's a problem if employees and officials are not pursuing major programs and tasks, instead doing extra activities to pursue income. For example chasing the number of patients to get medical services, cooperation with certain drug products with a secret. Increase the training out of the area so as to reduce the hourskerjannya. Indeed there is a tendency, but it depends on the leader of the hospital how to manage it (Interview, August 19, 2016).

Pursuit of prestige and income can also occur in the form of projects and activities that occur within an institution. Parties within the institution both alone and in cooperation with outsiders utilize programs, projects and activities to pursue revenue or prestige both legal and contrary to the rules. The researcher found the problem of tendering the construction of two new buildings at Bahteramas Hospital which happened in 2011. Commission of Business Competition Supervisor (KPPU) found a case of conspiracy of the construction of service building and first-class care building of VIP Bahteramas Hospital Southeast Sulawesi budget year 2011, namely decision number 4 / KPPU -L / 2012.Competition supervisory commission in 2012 provides a fine to two contractors involved. In the package of care buildings and service buildings there are six companies participating in the tender. The value of the maintenance building project which was won by the waskita works of Rp. 68.7 billion and service buildings won by adhi works around Rp. 91.91 billion. In addition, the committee procurement of goods / services APBD (procurement of construction services / consultants) scope of public hospitals Southeast Sulawesi Province budget year 2011 also became reported in the alleged conspiracy. KPPU has imposed a fine of Rp. 3.16 billion to waskita works and Rp. 4.47 billion to adhi works.

KPPU stated that both contractors mentioned focus on one package only from the beginning, namely the clairvoyant works for the package of care building and adhi works for the service building package. In order to win the desired package, both companies manage the high bid value submitted. The tender committee is considered to eliminate the principle of openness and other tender participants' chance to win the project because it does not announce and execute a clear tender bidding procedure. They are also considered not to prepare the tender documents properly at registration, no competent committee members in evaluating the installation of medical gases, and changing the announcement of the tender process schedule. Although appealed to the appeal to the Supreme Court, the decision remained the same that there was a violation of business competition and still be fined. Based on the above description occurred moral hazard in the pursuit of revenues made unscrupulous hospital, Southeast Sulawesi provincial government bidding committee with two state-owned construction that waskita and adhi works. Whereas business actors in conducting the tender should done with honest in order to inhibit unhealthy business competition.

\section{Information Distortion:-}

By definition, information distortions take place when agents as an institution or some staff member provide or tempt to provide false information about their performance from principal oversight. This can happen by providing performance information that stretches the organization's efforts and the results either too positive or negative (overstate or reduce information). Agencies can be motivated to report information that is not genuine to the 
principal, especially if information relates to agency performance measurements. Deputy director of 3 hospitals, AK says :

We always provide reports as reality whether it reaches the target or not. We dare not give the wrong report. It deals with trust (Interview, August 18, 2016).

Meir (2000) distinguishes four motivations for organizational distorting information ie performance gaps (inadequate), insufficient resources, overwhelmed on task demand and variations in bureaucratic oversight levels. Performance gaps, are deficiencies in task performance can lead individuals or institutions distorting supervisory information .For example, an organization that faces a lot of pressure to improve its performance in the next year. Because real performance improvements will be very difficult and time consuming, organizations may be tempted to bias actual achievement figures. Deceiving can also happen when an organization feels the task request to them is too difficult compared to the resources they receive. To meet government and community expectations and receive more resources or funding, organizations are tempted to either provide their performance too well or positively, or information is too minimal or low. IrbansusInspektorat Southeast Sulawesi, S said:

In examining the RSU report, sometimes there are differences in reports with the results of the examination, but that can usually be explained through the asisitensi. The hope can be improved in the future (Interview, August 19, 2016).

\section{Opportunity of Cross Subsidy:-}

The cross subsidy opportunity, can be understood as an activity in which an organization carries an activity device that is neither utility nor productive. Even if activities earn income but do not cover their costs. Under these circumstances possible information asymmetry emerges. Cross subsidies are usually motivated by pressure to raise the level of individual institutions or prestige. Therefore, the priority of an agency cross-subsidy is to find a set of these profitable activities that attract government funding and where agents can and will produce activities by minimizing costs. Deputy Director of 3 Hospital, AK explains:

All programs and activities at the hospital have been in the RAB, so that if there is an activity to earn income or issue something that is not there obviously will not be done. The cross subsidy opportunity means adding no actual costs or low production or earnings prices that are then charged and reported more on the state budget making it obviously a problem. To my knowledge this can happen in service through BPJS. The problem that often arises is the difference in the calculation of the number of people and drugs used which we then claim to the government. But certainly not done deliberately by us. (Interview, August, 19 2016).

Moral hazard behavior should be avoided in every health service, including hospital services, given the effects of moral hazard either in the form of laziness, the pursuit of income, the cross subsidy opportunism and the manipulation of the report. Overall, opportunistic behavior reduces organizational productivity. Productivity reductions result from reducing the efficiency and effectiveness of the use of government resources.

From the description above, there is a potential for hospitals to produce less service outcomes than produce without the emergence of opportunism. For example, laziness and the pursuit of prestige have reduced the effect of the expected output because they use resources for other purposes. Opportunity hospital opportunism is also reducing effectiveness, including service quality and service process and output. For example, laziness from employees leads to absenteeism but its existence is less useful. From what is stated above it can be said that this practice occurs in hospitals, and this indicates that there is still information asymmetry between the provincial government and rsud causing adverse selection problems or Moral hazard. Thus, if this practice continues, it will hamper the process of service to the community.

In the agency theory there are actually two possible principals for addressing agency opportunism ie contracts based on behavior and contracts based on outcomes. In behavior-based arrangements, provincial governments as principals do a great deal of reinforcement in monitoring and control procedures in relation to hospitals. In general, procedures can be taken such as report requests, direct visits, review and evaluation focusing on monitoring productive activities, with the main objective of informing the government of how the organization of the RSUD behaves in economic and operational sides. The second option is output-based settings. In this way the provincial government can prevent moral hazard problems by offering outputs associated with incentives for hospitals. The general objective of output-based arrangements is to reduce conflicts of interest by harmonizing the formal and operational 
objectives of hospitals with the provincial government. If the RSUD performs well, their budget will be increased, if performance is less successful, they will receive lower funding. By organization-based output arrangements through performance-based financing practices that are constructed with output-based funding formulas. However, there is a problem as Ekanayake (2004) argues, which suggests that when principals place more emphasis on output control, both principals and agents can observe the resulting outcomes but the efforts used by the agent can only be detected by the agent while the principal can not know.

In fact, in hospitals, behavior-based arrangements are more often done by the provincial government ie report requests, direct visits, reviews and evaluations that focus on monitoring productive activities. Although output-based arrangements are also performed, for example, medical services or remuneration. Because of this choice, controlling behavior in monitoring agency efforts, this is not satisfactory for agents due to over-supervision which can be more problematic if incentives are felt low and unfair.

The problems that arise in health services are related to information asymmetry although not complex but occur in Bahteramas hospitals. In addition to the selection of contracts based on dominant behavior, this is also related to the willingness and capacity of employees there. Finally there should be adverse selection and moral hazard at some level, but the mechanisms provided in the contract based on selected behaviors such as direct supervision, report retrieval and monitoring of key activities may curb the opportunism of hospitals as agents. This is because the system can inform the provincial government (principal) about what the RSUD actually does.

The incentives provided by the principal (provincial government) to agents (RS Bahteramas) in the form of media services, provincial and other basic benefits should be able to suppress agency opportunism. In fact, the opportunism of agents in the form of moral hazard and adverse selection is still occurring in Bahteramas hospitals, so incentives are less able to suppress agency opportunism. Thus, linking incentives to performance is one way to reduce agency conflicts that are not proven or less proven in this study. The study also states that not always incentives linked to performance can help to overcome moral hazard problems as evidence of existing incentives is less encouraging and motivating organizations and individuals to optimize their business.

\section{Chapter V:-}

\section{Conclusion:-}

This study suggests that incentive incentives can not help improve performance and overcome the moral hazard problems. Incentives are less encouraging and motivating organizations and individuals to optimize their business. Adverse Selection and Moral hazard still occur both potential and factual. It can be said that the implementation of health services in hospitals bahteramas also involves aspects of adverse selection and moral hazard.

\section{Bibliography:-}

1. Akerlof, G.A.1970. The Market for Lemons: Quality Uncertainty and the Market Mechanism. Quarterly Journal of Economics 84 (3), 488-500.

2. Bahteramas General Hospital: General Hospital Book of Bahteramas General Hospital of Southeast Sulawesi 2015.

3. Barney, J.B. \&Ouchi, W.G. Eds.1986.Organizational Economics.San Francisco: Jossey - Bass.

4. Bergen, M, Dutta, S \& Walker. 1992. Agency Relationship in Marketing: a Review of the Implications and Applications of the Agency and Related Theories. Journal of Marketing 56.1-24.

5. Bohte, J and Meir J. 2000. Goal Displacement : Assessing the Motivation for Organizational Cheating.Public Administration Review 60. 173-1.

6. BPK Representative Board of Southeast Sulawesi: Notes to the Financial Statements ofSoutheast Sulawesi Province For Year Ended 2014.

7. Creswell, W. Jhon. 2003. Research Design Qualitative \& Quantitative Approach, Sage. London-New Delhi.

8. Decree of the Minister of Health of the Republic of Indonesia no. 550 Year 2009 About Hospital Performance Assessment.

9. Desai, AsahayBhalchandra. 1998.A Study of the Relationship Between Changes in the Corporate Governance Mechanism: CEO Turnover and Performance in Declining Firms. Dessertation, Doctor of Philosophy Degree, Memphis University.

10. Eisenhardt, Katleen M. 1989. Agency Theory: An Assessment and Review. Academy of Management Review. Vol. 14 No. 1. 
11. Ekanayake, Samson. 2004. Agency Theory, National Culture and Management Control Systems. Journal of the American Academy of Business. Vol 4. Pp: 49 - 54.

12. Irawan, Prasetya. 2006. Qualitative and Quantitative Research for Social Sciences.Jakarta: Department of Administrative Sciences FISIP-UI.

13. Killick, T. 1997. Principals, Agents and The Failings of Conditionality. Journal of International Development.Review.Vol. 14 No. 1.

14. KivistoJussi. 2007. Agency Theory as a Framework for the Government - University Relationship.Tampere University.

15. Miles, Mathew and Huberman, 1994. Qualitative Data Analysis An Expanded Sourcebook. California: Sage Publication, Inc.

16. Moleong, Lexy J., 1994. Qualitative Research Methodology. Bandung: PT. Youth Rosdakarya.

17. Government Regulation No. 23/2005 on Financial Management of Public Service Bodies

18. Scott, W.R. 1995. Institutions and Organizations. Thousand Oaks, CA: Sage Publications, Inc. 